\title{
ANÁLISE DE SOBREVIVÊNCIA E GERMINAÇÃO EM PLANTIOS DE Araucaria angustifolia DERIVADO DE MUDAS E SEMENTES
}

\author{
SURVIVAL AND GERMINATION ANALYSIS IN PLANTATIONS OF Araucaria angustifolia \\ DERIVED FROM SEEDLINGS AND SEEDS
}

\author{
Jéssica Caroline Maran ${ }^{1}$ Maria Augusta Doetzer Rosot ${ }^{2}$ Maria Izabel Radomski ${ }^{3}$ Betina Kellermann ${ }^{4}$
}

\section{RESUMO}

O bioma florestal mais característico do Sul do Brasil é a Floresta Ombrófila Mista, fortemente marcada pela presença da espécie Araucaria angustifolia. Entretanto, a exploração irracional e descontrolada desta espécie reduziu drasticamente sua área de ocorrência a $2 \%$ de sua área original. Assim, esforços devem ser feitos para auxiliar e promover sua regeneração natural, visando a sua preservação e o uso sustentável de seus recursos econômicos. Com o objetivo de avaliar a germinação, sobrevivência e predação de mudas e sementes de Araucaria angustifolia foi implantado um experimento em delineamento inteiramente casualizado, no qual foram investigados os efeitos de dois fatores com dois níveis cada (tipo de plantio: puro/ misto; material plantado: mudas/sementes), com três repetições, perfazendo um total de quatro tratamentos. Após 14 meses restaram 17\% das covas ocupadas por mudas e 14\% das ocupadas por pinhões; $60 \%$ das sementes germinadas foram consumidas pela fauna; o percentual de sobrevivência médio das mudas foi de $41,1 \%$ no plantio puro e de $20,0 \%$ no plantio misto. No tratamento misto, as perdas de sementes, devido à ação fauna, foram menores $(42,2 \%)$ quando comparadas ao tratamento puro $(68,9 \%)$; o contrário foi válido no caso das mudas.

Palavras-chave: fauna; predação; pinhão.

\begin{abstract}
The most characteristic forest type of southern Brazil is the Araucaria Forest, strongly marked by the presence of the species Araucaria angustifolia. However, the overexploitation of the species reduced its range to $2 \%$ of its original area. Efforts must be made to support and promote its natural regeneration, seeking the preservation and sustainable use of its economic resources. Therefore, an experiment was conducted to evaluate germination, survival and predation rates of seeds and seedlings of Araucaria angustifolia, analyzed as a randomized factorial design with two factors with two levels each (type of plantation: pure/ mixed; raw material: seeds/seedlings), totaling four treatments, with three replicates each. Fourteen months after planting only $17 \%$ of the seed holes contained live plants; $14 \%$ of planted seedlings survived; $60 \%$ of the seeds were consumed by animals. Seedling survival was $41.1 \%$ in the "pure" treatment and $20 \%$ in the mixed treatment. In the mixed treatment, seed losses due to fauna attack were lower (42.2\%) compared to the 'pure' treatment (68.9\%); the opposite behavior was observed in the case of seedlings.
\end{abstract}

Keywords: fauna; predation; Paraná pine nuts.

1 Engenheira Florestal, Mestranda pelo Programa de Pós-Graduação em Engenharia Florestal, Universidade Federal do Paraná, Av. Pref. Lothário Meissner, 900, Jardim Botânico, Campus III, CEP 80210-170, Curitiba (PR), Brasil. Bolsista Capes. jess.maran@gmail.com

2 Engenheira Florestal, Dra ${ }^{\mathrm{a}}$., Pesquisadora da Embrapa Florestas, Estrada da Ribeira, Km 111, CEP 83411-000, Colombo (PR), Brasil. augusta.rosot@embrapa.br

3 Engenheira Agrônoma, Dra ., Pesquisadora da Embrapa Florestas, Estrada da Ribeira, Km 111, CEP 834111-000, Colombo (PR), Brasil.maria.radomski@embrapa.br

4 Bióloga, MSc., Bolsista DTI CNPq, Embrapa Florestas, Estrada da Ribeira, Km 111, CEP 834111-000, Colombo (PR), Brasil. betina.kellermann@gmail.com

Recebido para publicação em 9/06/2014 e aceito em 26/03/2015 


\section{INTRODUÇÃO}

O bioma florestal mais característico no Sul do Brasil é a Floresta Ombrófila Mista (FOM) (BACKES, 2009b), fortemente marcada pela presença da espécie Araucaria angustifolia, a gimnosperma nativa de maior importância econômica e biológica do país (ANSELMINI, 2005). Originalmente, esta formação ocupava cerca de 20 milhões de hectares (BACKES, 2009a), distribuída nos estados do Paraná (40\%), Santa Catarina (31\%) e norte do Rio Grande do Sul (25\%), encontrandose menores agrupamentos em São Paulo (3\%), Rio de Janeiro, Minas Gerais e Espírito Santo, em áreas de altitude elevada (CARVALHO, 1994; BACKES, 2009a; GUERRA et al., 2000), além de países vizinhos como Argentina e Paraguai (CARVALHO, 1994; ANSELMINI, 2005). No entanto, estima-se que hoje existam apenas 400 mil hectares desta área (GUERRA et al., 2000).

A intensa exploração da Araucaria angustifolia no primeiro ciclo econômico do Sul do Brasil é responsável pela drástica redução de sua área de ocupação original (ANSELMINI, 2005). Os resultados do Inventário Florestal Nacional - Paraná e Santa Catarina mostraram que, já na década de 1980, os remanescentes na Floresta Ombrófila Mista estavam exauridos e degradados, porém, ainda existiam algumas florestas com um volume expressivo de madeira de araucária.

Embora abundante nos remanescentes da tipologia FOM, vários estudos fitossociológicos em matas com araucária mostram que esta espécie apresenta uma baixa regeneração natural em áreas nativas, observando-se que a maioria das árvores presentes nas florestas naturais já se encontra no estágio intermediário ou adulto, sendo raras as plantas jovens (LAMBERTS, 2003; MULLER, 1986). Esses poucos indivíduos não são suficientes para garantir a regeneração natural da espécie (MULLER, 1986), uma vez que esta depende de um ambiente perturbado para se regenerar, devido à sua característica de espécie secundária longeva, porém, com temperamento pioneiro (CARVALHO, 1994).

Muitos fatores bióticos e abióticos influenciam o índice de regeneração natural de Araucaria angustifolia. Mello Filho et al. (1981) atribuíram ao consumo das sementes um dos principais fatores limitantes para a regeneração desta espécie. No caso da sobrevivência de mudas, Sanquetta et al. (2005) associam o maior vetor de mortalidade ao grande fluxo de animais dentro da floresta.

As sementes de araucária, popularmente conhecidas como pinhões, servem de alimento para grande parte da fauna que habita as florestas subtropicais brasileiras (MELLO FILHO et al., FABER, 1981). A importância do seu consumo por animais silvestres dá-se pelo fato de a maturação e queda destas sementes ocorrer na época de escassez de outras fontes de alimento, sobretudo nos meses de abril, maio e junho (MULLER, 1986). Os animais que se alimentam dos pinhões, consumindo uma porção suficiente para inviabilizar a sua germinação, são considerados predadores de sementes, e podem exercer uma forte influência na população das plantas, uma vez que a predação de sementes em espécies arbóreas tropicais é, em geral, elevada, variando entre 75 a 90\% (VIEIRA; IOB, 2009).

Camundongos, pacas, cotias, esquilos, gralhas e ouriços estão enquadrados na lista de animais predadores de sementes da araucária (MULLER, 1986). Papagaios, gambás, bugios, macacos, quatis, veados, esquilos e capivaras são alguns dos outros animais presentes nessa lista (VIEIRA; IOB, 2009). Os camundongos são os maiores responsáveis pelo consumo de pinhões e, devido à sua alta população, são também os que causam maiores impactos negativos na regeneração da espécie (MULLER, 1986; VIEIRA; IOB, 2009). Entretanto, alguns destes animais, apesar de consumidores, trabalham na dispersão das sementes, como é o caso das gralhas, papagaios, cotias e esquilos (VIEIRA; IOB, 2009).

Problemas de predação pela fauna foram reportados por Rosot et al. (2007) também em plantios de recuperação de áreas degradadas e de enriquecimento com Araucaria angustifolia, observando-se a arranquia de mudas recémplantadas em busca do pinhão ainda ligado ao sistema radicular em formação. Por outro lado, tampouco a semeadura direta é garantia de êxito no estabelecimento de povoamentos, já que as sementes ficam muito suscetíveis ao ataque de roedores, mesmo quando são depositadas várias sementes por cova (BANCO REGIONAL DE DESENVOLVIMENTO DO EXTREMO SUL, 2005). Carvalho (1994) afirma que tanto aves quanto mamíferos ocasionam danos a plantios por semeadura direta. O perdiz (Rhynchotus rufescens rufescens) alimenta-se dos brotos recémgerminados, arrancando também as sementes para 
consumir a raiz da nova planta.

Outro predador ainda pouco estudado, mas capaz de causar grandes prejuízos a plantios de araucária, é o macaco-prego (Sapajus nigritus). Esta espécie é característica da Mata Atlântica, de hábito alimentar onívoro, com grande adaptabilidade aos ambientes alterados pelo homem, podendo sobreviver em áreas de florestas fragmentadas e degradadas, como é o caso da FOM, desde que tenha acesso a outras fontes alimentares, como as plantações ao redor de seu ambiente (LUDWIG et al., 2005).

Tendo em vista a importância da araucária e o estado de conservação dos remanescentes florestais que a abrigam, torna-se essencial o entendimento dos processos de predação de sementes e mudas em estratégias que visam ao plantio desta espécie. Assim, este trabalho tem como objetivo avaliar quantitativamente a germinação de sementes, a sobrevivência de mudas e plântulas recém-emergidas, bem como a predação destes dois materiais (mudas e sementes), em plantio de Araucaria angustifolia, em uma área contígua a um fragmento de FOM.

\section{MATERIAIS E MÉTODOS}

\section{Área de estudo}

A área de estudo localiza-se na Estação Experimental da Embrapa (EEEC), situada no município de Caçador, região centro-oeste do estado de Santa Catarina, entre as coordenadas geográficas $26^{\circ} 50^{\prime}$ e $26^{\circ} 55^{\prime}$ de Latitude Sul e $50^{\circ} 05^{\prime}$ e $51^{\circ} 00^{\prime}$ de Longitude Oeste. Representa um dos maiores remanescentes contínuos com vegetação característica da região fitogeográfica Floresta Ombrófila Mista, parte do domínio Mata Atlântica, compreendendo uma superfície total de aproximadamente 1.194 hectares (ROSOT et al., 2007). Atualmente, a EEEC concentra grande parte das pesquisas em silvicultura e manejo de florestas naturais desenvolvidas pela Embrapa Florestas, incluindo ensaios de enriquecimento, adensamento e plantios de espécies nativas.

A altitude local varia de 1.000 a 1.100 metros, com clima do tipo $\mathrm{Cfb}$, conforme a classificação de Köppen, com verões quentes e invernos frios, com a presença de geadas. As classes de solo predominantes na área de estudo são Cambissolo + Neossolo, com relevo variando de suave a ondulado (ROSOT et al., 2013). Mais especificamente, o experimento foi implantado em uma área da EEEC anteriormente ocupada por agricultura e com predomínio de Nitossolo.

Cerca de 94\% da superfície da EEEC possui cobertura florestal em diversos estágios de desenvolvimento e graus de conservação. Além disso, abriga uma fauna característica desta tipologia florestal. Segundo Tortato (2008), foram registradas 25 espécies de mamíferos nativos, incluídas em 16 famílias: Didelphis albiventris, Dasypus novemcinctus, Cabassous tatouay, Tamandua tetradactyla, Alouata guariba, Sapajus nigritus, Cerdocyon thous, Leopardus pardalis, Leopardus tigrinus, Leopardus wiedii, Eira barbara, Nasua nasua, Procyon cancrivorus, Pecari tajacu, Mazama guazoubira, Mazama nana, Akodon sp., Oligoryzomys nigripes, Oryzomys russatus, Thaptomys nigrita, Hydrochoerus hydrochaeris, Sphiggurus villosus, Cuniculus paca, Dasyprocta azarae, Myocastor coypus. Entre os mamíferos selvagens exóticos foi registrado Lepus europeus, Sus scrofa e a espécie asselvajada Sus scrofa domestica.

Resultados de um estudo realizado por Tortato et al. (2009) na Estação Experimental da Embrapa mostraram que a mastofauna utiliza as subtipologias da Floresta de Araucária de forma distinta, o que se evidenciou principalmente ao se comparar parcelas com maior ou menor presença de bambus. A espécie Sapajus nigritus, conhecida popularmente como macaco-prego, tem preferência pelas araucárias, observando-se grandes quantidades de sementes imaturas atiradas ao solo por este animal. Além disso, o uso do solo predominante no entorno da área de estudo (reflorestamento de Pinus sp., vegetação nativa e áreas de agricultura), constitui um ambiente favorável para a manutenção de grandes grupos destes primatas. O porco doméstico, oriundo das propriedades vizinhas, ao cruzar-se com o javali, originou o porco asselvajado. Sua presença dentro da EEEC é extremamente danosa, pois causam a destruição da regeneração por onde passam, retiram a casca das árvores e atraem a presença de caçadores, que também procuram por outros animais selvagens.

\section{Delineamento experimental e tratos culturais}

Foram avaliadas a germinação, a sobrevivência e a predação de mudas e sementes de araucária em um experimento instalado na EEEC, analisado como um ensaio fatorial $2 \times 2$, sendo os 
fatores:

- $\quad$ Material plantado, com dois níveis: muda e pinhão;

- Arranjos de plantio, com dois níveis: puro (só muda ou só pinhão) e misto (muda e pinhão);

Considerando-se um delineamento inteiramente casualizado, a combinação de níveis e fatores gerou quatro tratamentos com três repetições cada: Tratamento I. Plantio puro de mudas; Tratamento II. Semeadura pura de pinhões; Tratamento III. Plantio de mudas em parcela mista; Tratamento IV. Semeadura de pinhões em parcela mista.

No entanto, como as unidades experimentais dos tratamentos III e IV são coincidentes (tratamentos mistos), o ensaio contém nove parcelas no total. Cada parcela foi composta por seis linhas e cinco fileiras, formando um retângulo de dimensões $30 \mathrm{x}$ 25 metros, com espaçamento de $5 \times 5$ metros entre as covas, totalizando 30 covas por parcela. Portanto, o experimento foi composto por 270 covas, sendo 135 destinadas ao plantio de mudas e 135 destinadas à semeadura de pinhões. Considerando o número de três pinhões por cova, o número total de sementes utilizadas na implantação foi de 405. A superfície total do experimento foi de $6.750 \mathrm{~m}^{2}$.

$O$ plantio e a semeadura ocorreram no mês de maio do ano de 2012. O preparo da área para instalação das parcelas incluiu roçada prévia, passagem de grade e de subsolador a $40 \mathrm{~cm}$. As covas foram executadas com auxílio de broca acoplada a trator. Os tratos culturais efetuados no período de condução do ensaio foram a limpeza do terreno e o coroamento periódico em torno das covas com a presença de mudas e de pinhões, bem como o combate a formigas.

Nas parcelas com plantio puro de mudas de Araucaria angustifolia (Tratamento I) foram utilizadas mudas produzidas em viveiro com sementes oriundas da própria área de estudo, coletadas no ano anterior à instalação do experimento. Na época do plantio, as mudas tinham 10 meses de idade e uma altura média de $25 \mathrm{~cm}$. Foram utilizados $300 \mathrm{ml}$ de hidrogel e $100 \mathrm{~g}$ de adubo NPK por cova.

Nas parcelas em que ocorreu a semeadura pura (Tratamento II) utilizaram-se três pinhões por cova, obtidos por meio de coleta, com um dia de antecedência ao plantio, de diferentes localidades dentro da área de estudo (EEEC), não recebendo qualquer tratamento repelente ou fungicida. Neste caso, também foram utilizados $100 \mathrm{~g}$ de NPK por cova.

Ascovas das parcelas mistas correspondentes aos tratamentos III e IV receberam alternadamente mudas e sementes, nas mesmas quantidades, com os mesmos tratos culturais e materiais utilizados nos tratamentos I e II.

Não foi realizado nenhum replantio para evitar a introdução de mais uma fonte de variação, representada pelas diferentes épocas e intensidades de replantio e/ou semeadura.

\section{Avaliação e monitoramento}

O monitoramento foi realizado mensalmente, a partir do mês de setembro de 2012, quando o plantio completou quatro meses. Avaliou-se a sobrevivência das mudas, bem como a germinação dos pinhões e os possíveis danos ocorridos aos indivíduos pela ação da fauna local.

A situação das mudas foi enquadrada dentro das seguintes categorias: muda "viva", no caso de sobreviventes normais, sem problemas fitossanitários ou mudas sobreviventes, mas com alguns sinais de clorose - apresentando algum problema fitossanitário ou deficit nutricional; muda "morta", no caso de plantas em pé, completamente secas; e muda "arrancada", no caso de mudas que foram removidas, devido à ação predatória de animais selvagens ocorrentes na área, mas encontradas ao lado de suas covas, mortas; também foram enquadradas, nesta última categoria, as plantas desaparecidas, possivelmente também predadas por ação de animais.

No caso das covas em que ocorreu a semeadura dos pinhões foi verificada a presença, ou não, de plântulas recém-emergidas, sendo categorizadas como covas com "germinação de 0 pinhões", "germinação de 1 pinhão", "germinação de 2 pinhões" e "germinação de 3 pinhões". Durante os meses de acompanhamento do ensaio, após o aparecimento das plântulas, observou-se a remoção dos pinhões germinados de suas covas, devido à predação da fauna local; tais sementes foram enquadradas na categoria "pinhão consumido". Plântulas que se encontravam completamente secas foram enquadradas na categoria "plântula morta".

A localização espacial de cada cova foi representada por pontos em um Sistema de Informações Geográficas (SIG), construído com a utilização do software QGIS, e os dados de campo foram progressivamente inseridos na respectiva tabela de atributos do SIG. Os principais campos dessa tabela 
são:

- $\quad$ Número de identificação da parcela;

- Número de identificação da cova;

- Identificação do arranjo e plantio (puro pinhão; puro muda; misto);

- Identificação do material plantado (muda ou pinhão);

- $\quad$ Situação no mês $X_{1}, X_{2}, X_{3}, \ldots, X_{14}$ (um campo para cada mês, podendo assumir as categorias de "viva", "morta", "arrancada", "germinação de 0 pinhões", "germinação de 1 pinhão", "germinação de 2 pinhões", "germinação de 3 pinhões", "pinhão consumido", "plântula morta").

\section{Análise dos dados}

Por meio de análises de variância (ANOVA) foram avaliados os efeitos simples dos fatores e sua interação de forma separada para as variáveisresposta percentual de germinação e percentual de sobrevivência. As análises tiveram por objetivo responder às seguintes questões:

- Qual o percentual médio de germinação dos pinhões?

- Qual o percentual médio de sobrevivência ao se plantar apenas mudas (arranjo de plantio puro); ao se fazer semeadura de pinhões (arranjo de semeadura pura); ao se plantar mudas e efetuar a semeadura (arranjo misto, com muda e pinhão, mas analisados separadamente)?

- Existe diferença significativa entre os percentuais de sobrevivência em cada tratamento supramencionado?

- Em qual tratamento o arranque e mortalidade foram maiores?

- $\mathrm{O}$ arranjo utilizado (puro ou misto) influencia o percentual de sobrevivência?

Com relação às variáveis-resposta "mortalidade" e "arranquia" de plântulas, em se verificando a existência de diferença significativa entre os tratamentos conforme resultados da ANOVA, foi efetuado um teste de Tukey para a comparação de médias dos tratamentos.

\section{RESULTADOS E DISCUSSÃO}

\section{Germinação de pinhões e sobrevivência de plântulas recém-emergidas}

Considerando-se o percentual de germinação acumulada, tanto no que se refere à germinação dos pinhões quanto à ocupação das covas pelos pinhões germinados, é possível observar que até o quarto mês após a semeadura ocorreu baixa germinação das sementes (Figuras 1 e 2). A Figura 1(A) mostra que até este mês, apenas $10 \%$ das sementes haviam germinado (Tratamento II); no caso do plantio em arranjo misto (Tratamento IV) este índice foi ainda menor, pouco mais de $2 \%$, como pode ser visto na Figura 2(A). No entanto, para ambos os tratamentos, entre o quarto e o quinto mês ocorreu um incremento no fenômeno germinação, que atingiu valores de quase $48 \%$ e $34 \%$ para a semeadura em parcelas puras e mistas, respectivamente. Também se observa que, apesar de os índices de germinação para as parcelas mistas serem menores inicialmente (Figura 2A), ocorre um incremento desse fenômeno, que continua a se elevar em níveis significativos até o oitavo mês, chegando a ultrapassar, com pequena diferença, os valores de germinação obtidos no tratamento com semeadura pura.

Considerando todas as sementes plantadas por cova, após os 14 meses de plantio, o percentual de germinação obtido no experimento foi de $55 \%$ para as parcelas em que foi realizada somente a semeadura, com 1,78 plantas germinadas por cova e de $59 \%$ para as parcelas mistas, com 1,66 plantas germinadas por cova. A germinação média, considerando os arranjos puros e mistos, foi igual a $57 \%$. Esses são valores mais elevados do que aqueles obtidos por Jankauskis (1972), que observou 1,2 mudas por cova, semeando quatro pinhões, em condições silviculturais similares às do presente estudo.

O percentual médio de covas com plântulas recém-emergidas nas parcelas correspondentes a arranjos puros (Tratamento II) foi de $92 \%$; nas parcelas mistas (Tratamento IV), o percentual de covas com pinhões germinados foi de quase $89 \%$, um valor consideravelmente mais alto do que os 53\% de ocupação das covas encontrada por Jankauskis (1972), mesmo utilizando um pinhão a mais por cova.

Entretanto, os valores supracitados são referentes à germinação acumulada dos pinhões, e não refletem a ação da fauna predadora de sementes, nem a mortalidade das plântulas recémemergidas. Ao considerar tais fatores, percebe-se que o consumo dos pinhões pela fauna acarretou perdas consideráveis, interferindo de maneira direta no percentual de germinação final efetivo do experimento, que foi de apenas $14 \%$ no plantio puro e de $28 \%$ no plantio misto, quando comparados aos 
percentuais de $55 \%$ e $59 \%$, obtidos quando não foram consideradas tais perdas.

A predação de sementes pela fauna observada no ensaio foi de quase $69 \%$ para os arranjos puros e de $42 \%$ para os mistos, perfazendo uma média de ataque a $60 \%$ dos pinhões plantados no experimento. Entre o quinto e sexto mês, a partir do plantio (outubro e novembro), ocorreu uma alta taxa de predação das sementes em ambos os tratamentos, reduzindo bruscamente a quantidade pinhões germinados. Isso, eventualmente, pode estar associado à diminuição da quantidade de pinhões disponíveis na floresta, em função da época do ano e o consequente aumento da predação por parte da fauna, que explora outras áreas em busca de alimento.

Os pinhões que germinaram, e não foram removidos, apresentaram baixo índice de mortalidade, com apenas 3\% nos plantios puros e $2 \%$ no plantio misto. Ao décimo quarto mês de observação, restavam apenas $14 \%$ dos pinhões semeados nas parcelas puras - correspondentes à ocupação de $20 \%$ das covas. No caso das parcelas mistas, este número foi o dobro, tendo $28 \%$ das plântulas permanecido vivas, o que corresponde a uma ocupação de mais de $50 \%$ das covas das parcelas que haviam sido semeadas com pinhões.

Em condições ideais para a germinação, em laboratório, Kuniyoshi (1983) afirma que as sementes de Araucaria angustifolia apresentam uma ampla variação, podendo germinar de 0 a 90\%. Segundo Carvalho (1994), isto pode estar associado ao tempo de armazenamento dos pinhões, podendo a capacidade germinativa variar de $75 \%$, $45 \%$ e $45 \%$ quando armazenados após 60,90 e 120 dias, respectivamente, em ambientes com umidade relativa acima de $80 \%$. Em se tratando de pinhões recém-colhidos, $90 \%$ de germinação podem ser atingidos em condições ideais em laboratório. Em campo, as condições são muito mais variáveis do que as mantidas em laboratório, afetando os níveis de germinação.

Paludo, Mantovani e Reis (2011), durante levantamento em uma população natural de Araucaria angustifolia, encontraram plântulas não enraizadas, com características que indicavam terem sido arrancadas recentemente. Em geral, estas plântulas não possuíam os cotilédones e tampouco a gema apical, sugerindo a ocorrência de herbivoria. $\mathrm{O}$ mesmo padrão foi observado na área do presente
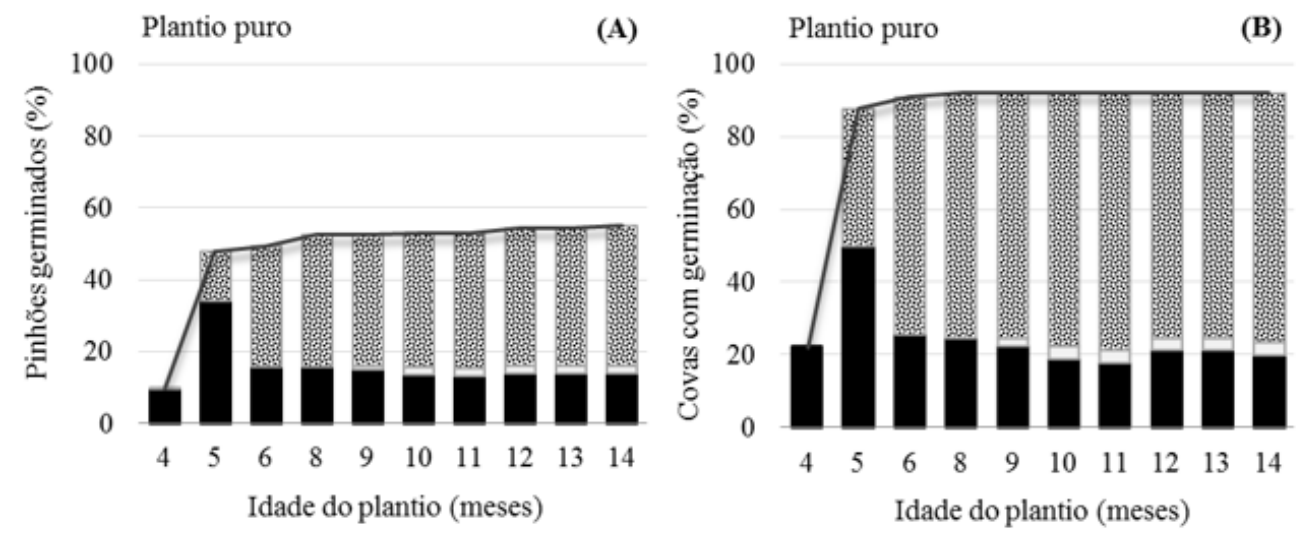

19:\% Pinhões/plântulas consumidos

$\square$ Plântulas mortas

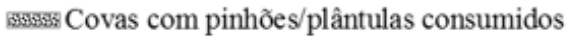

Covas com plântulas mortas

Covas com plântulas remanescentes

— Percentagem de ocupação acumulada das covas

B)

- Percentagem de germinação acumulada

FIGURA 1: Germinação e sobrevivência no tratamento puro de semeadura de pinhões: (A) Percentual médio acumulado de pinhões germinados, consumidos e remanescentes, em relação ao número de pinhões plantados; (B) Percentual médio acumulado de covas com pinhões germinados, ou remanescentes, e vazias, em relação ao número de covas com pinhões plantados.

FIGURE 1: Germination and survival in pure planting treatment with seeds: (A) Accumulated average percentage of seeds sprouted, consumed and remaining, in relation to the number of planted seeds; (B) Cumulative average percentage of holes with seeds sprouted, or remaining, and empty, compared to the number of holes planted with seeds. 

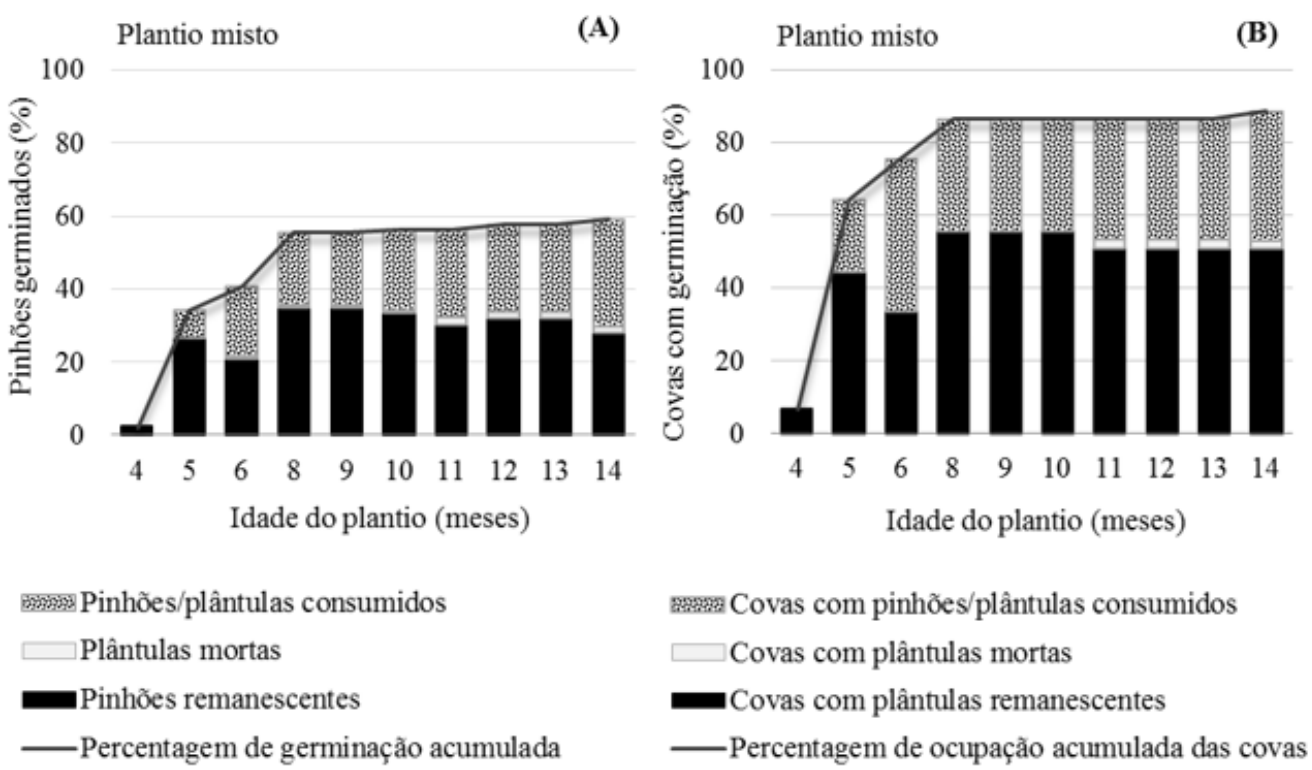

FIGURA 2: Germinação e sobrevivência no tratamento misto de semeadura de pinhões e plantio de mudas: (A) Percentual médio acumulado de pinhões germinados, consumidos e remanescentes, em relação ao número de pinhões plantados; (B) Percentual médio acumulado de covas com pinhões germinados, ou remanescentes, e vazias, em relação ao número de covas em que houve semeadura de pinhões.

FIGURE 2: Germination and survival in mixed planting treatment with seeds and seedlings: (A) Accumulated average percentage of germinated seeds, consumed and remaining, in relation to the number of planted seeds; (B) Cumulative average percentage of holes sprouted with seeds, or remaining, and empty compared to the number of holes planted with seeds.

estudo, embora algumas plântulas não tenham sido encontradas, não havendo indícios sobre predadores responsáveis por sua remoção. Em uma área de Floresta Ombrófila Mista degradada por fogo, na mesma Estação Experimental na qual o presente estudo foi realizado, Rosot et al. (2007) efetuaram o plantio de sementes de Araucaria angustifolia; no entanto, a quantificação da germinação dos pinhões não foi possível devido ao ataque do macaco-prego (Sapajus nigritus), que arrancou as plântulas recémemergidas para se alimentar da parte suculenta dos pinhões.

Considerando os baixos índices de mortalidade das plantas recém-emergidas - apenas $3 \%$ - pode-se atribuir o baixo percentual de plântulas remanescentes no décimo quarto mês ao consumo da fauna. Experimentos em que se disponibilizaram sementes de espécies nativas no interior de fragmentos da FOM resultaram em uma predação de até $95 \%$ das sementes de Araucaria angustifolia (GANADE;ZANINI, 2009), demonstrando o grande interesse da fauna nestas sementes como fonte de alimento. No entanto, o índice de mortalidade das plântulas recém-emergidas também foi influenciado pelas taxas de remoção ocasionada pela fauna, pois, caso não fossem predadas, tais plântulas poderiam, eventualmente, morrer por outras causas.

\section{Sobrevivência das mudas em plantios puros e mistos}

Até o sexto mês a partir do plantio, mais de $80 \%$ das mudas encontravam-se vivas, tanto no plantio puro quanto no arranjo misto (Tratamentos I e III, respectivamente). No entanto, entre o sexto e oitavo mês (de novembro a janeiro) ocorreu um incremento significativo no número de mudas mortas: $44 \%$ das mudas oriundas do plantio puro e $62 \%$ do plantio misto morreram. Porém, a partir deste mês, as taxas de mortalidade se mantiveram estáveis (Figura 3), observando-se um percentual de sobrevivência das mudas no décimo quarto mês igual a $41 \%$ no plantio homogêneo e $20 \%$ no plantio misto. Carvalho (1981) encontrou um percentual de sobrevivência de $63 \%$, para um período de quatro anos após o plantio, realizado em uma área de FOM 


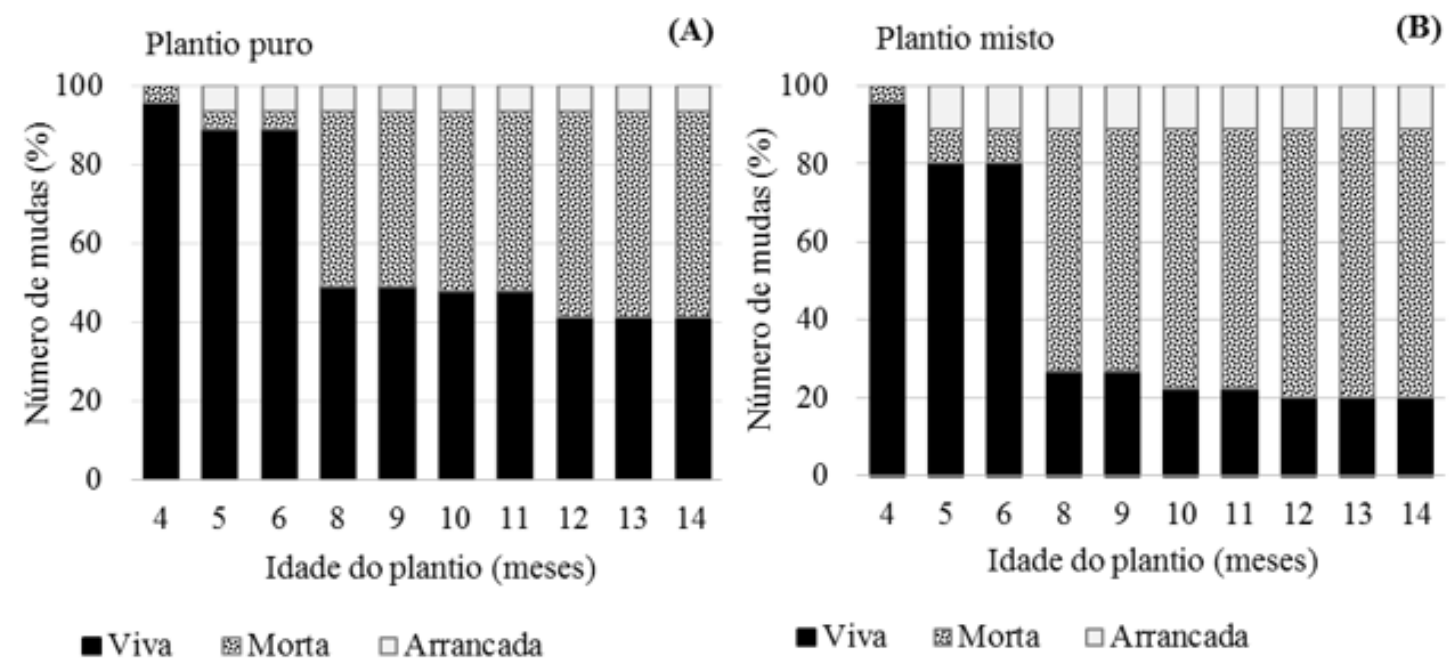

FIGURA 3: Percentual de sobrevivência, mortalidade e remoção de plantas causada pela fauna no plantio de mudas: (A) Plantio puro; (B) Plantio misto.

FIGURE 3: Percentage of survival, mortality and pullout caused by wildlife in planting seedlings: (A) Pure plantation; (B) Mixed plantation.

na Floresta Nacional (FLONA) de Irati. Segundo o autor, esse resultado está de acordo com o obtido por Muniz (1948 apud CARVALHO, 1981), porém, é quase duas vezes superior ao obtido por Fonseca et al. (1974) apud Carvalho (1981), que mais se aproximaria aos valores médios totais obtidos no presente estudo (34\%).

Quanto aos danos causados por ação da fauna pôde-se observar um padrão em ambos os tratamentos: mudas foram arrancadas somente entre o quarto e quinto mês (entre setembro e outubro), ocasionando uma perda de aproximadamente $7 \%$ no plantio puro e de $11 \%$ no plantio misto, não havendo ataques nos meses subsequentes (Figura 3). A remoção das mudas pode ter sido promovida pelo macaco-prego (Sapajus nigritus), à semelhança do ocorrido em outra área de plantio na EEEC, em que Rosot et al. (2007) observaram uma mortalidade de 49\% das mudas de Araucaria angustifolia após três meses de plantio, sendo $28 \%$ atribuída à ação do macaco-prego e $21 \%$ devido a outros fatores, tais como enovelamento de raízes e má qualidade das mudas. Outros autores relatam ocorrência de mortalidade associada à ação de animais selvagens predadores como catetos, cutias e outros roedores de menor porte em plantios de enriquecimento e adensamento com Araucaria angustifolia, variando de $26 \%$ (SANQUETTA et al., 2005) a $45 \%$ (SANQUETTA, 2007).
No presente estudo, $52 \%$ e $69 \%$ das mudas oriundas do plantio puro e misto, respectivamente, morreram, possivelmente devido a fatores de origem edáfica e climática e não pelo ataque da fauna ou outros agentes. Eventualmente a disponibilidade de sementes em parcelas contíguas ou na mesma parcela das mudas pode ter minimizado relativamente a predação sobre as mudas.

\section{Balanço geral}

No balanço final do experimento, temse um percentual de quase $70 \%$ de covas vazias, cujas mudas e pinhões germinados morreram ou foram arrancados por ação da fauna (Figura 4). Das covas ocupadas, $55 \%$ abrangiam o remanescente de mudas de araucária e 45\% as plântulas germinadas oriundas dos pinhões (17\% e 14\%, respectivamente, considerando-se o total de covas ocupadas remanescentes) (Tabela 1 ).

$\mathrm{Na}$ Figura 4 pode-se observar que as parcelas de número 4, 5, 7 e 9 - mais afastadas da floresta natural circundante ao experimento - apresentaram, respectivamente, $16,10,9$ e 5 plantas vivas aos 14 meses após o plantio. Comparando esses valores aos de 17, 8, 5, 4 e 8 plantas vivas correspondentes às parcelas $1,2,3,6$ e 8 , respectivamente, não é possível estabelecer uma relação direta da influência da proximidade da floresta e, consequentemente, 

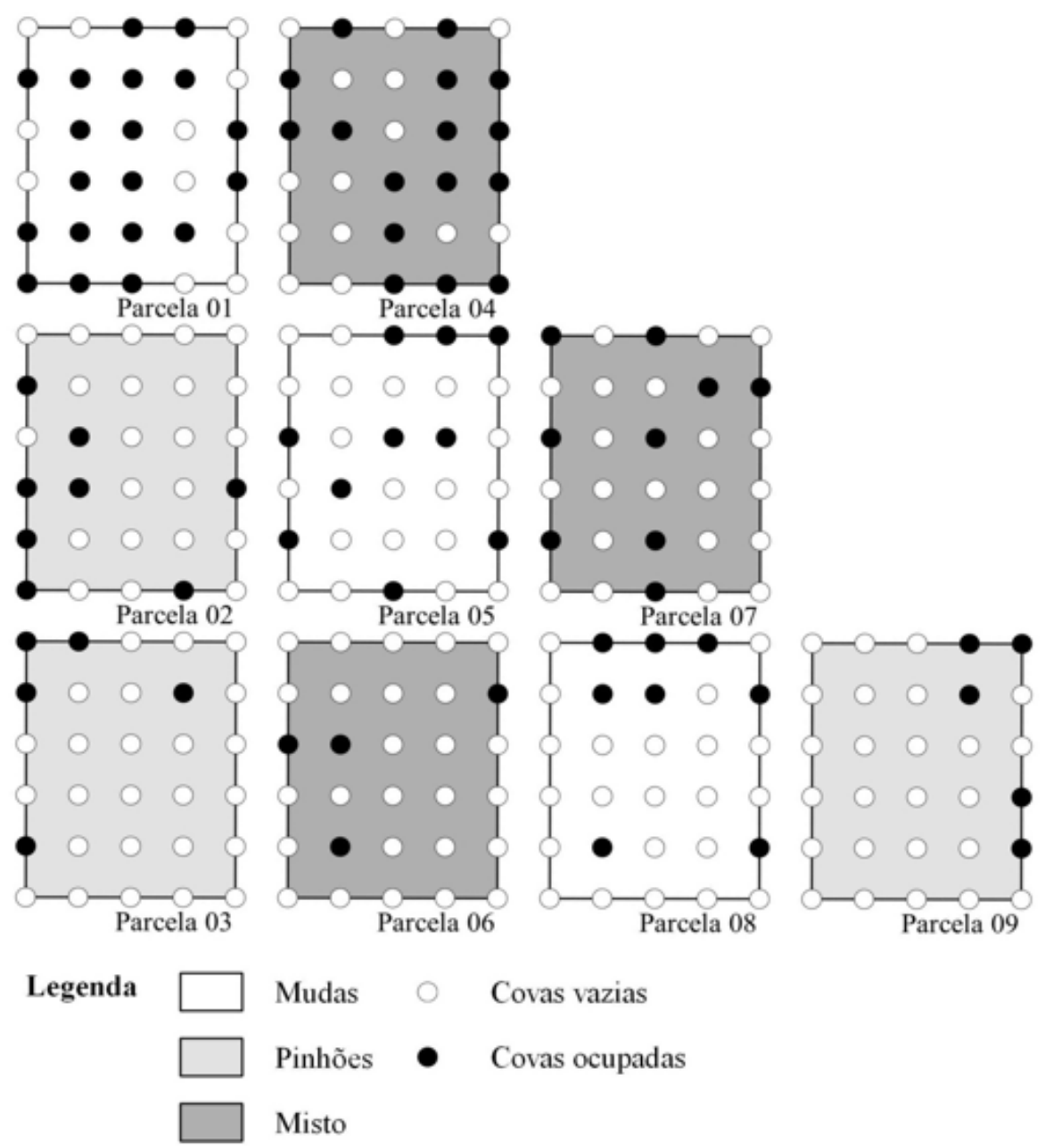

FIGURA 4: Situação do experimento aos 14 meses do plantio: covas ocupadas (mudas vivas; 1, 2 ou 3 pinhões germinados) e vazias (mudas mortas, pinhões não germinados, arrancadas).

FIGURE 4: Situation of the experiment at 14 months after planting: occupied holes (live seedlings, 1, 2 or 3 seeds germinated) and empty (dead seedlings, non-germinated seeds, pulled).

da fauna, sobre o percentual de sobrevivência de mudas e plântulas oriundas da semeadura de pinhões. De certa forma, esse resultado era esperado por se tratar de uma área pequena e relativamente isolada na Estação Experimental, sem circulação de pessoas exceto para a manutenção periódica do experimento.

Considerando as covas vazias, o que se observa é que o percentual de mortalidade das mudas $(42 \%)$ é bastante próximo ao percentual de perdas de pinhões por consumo da fauna (44\%), havendo poucas mudas arrancadas ou plântulas recém-emergidas mortas (Tabela 1). Provavelmente, a disponibilidade de sementes, um alimento de mais fácil acesso, tenha reduzido as taxas de predação da fauna sobre as mudas, diminuindo, então, os danos causados por esses agentes.
No entanto, as análises estatísticas executadas demonstraram que apenas o efeito do material (muda ou pinhão) é significativo (p-valor $=0,00015)$ no que diz respeito à mortalidade, não havendo influência do arranjo utilizado (plantio puro ou misto). Desta forma, os índices de mortalidade são os mesmos tanto no arranjo puro quanto no misto, uma vez que a interação entre o tipo de material e o arranjo utilizado não foi significativa, sendo a mortalidade do material "muda" sempre maior do que plântulas originadas do material "sementes" (Tabela 2).

Em contrapartida, considerando mudas e sementes arrancadas, além do efeito do material ser expressivo ( $\mathrm{p}$-valor $=0,000241)$, a interação entre o tipo de material plantado e o arranjo em que este se encontra também foi estatisticamente significativa 
TABELA 1: Percentual do número de covas ocupadas, e covas vazias, no décimo quarto mês após o plantio.

TABLE 1: $\quad$ Percentage of the number of occupied holes, and empty holes, fourteen months after planting.

\begin{tabular}{lccc}
\hline \multicolumn{2}{c}{ Covas Ocupadas (31,11\%) } & \multicolumn{2}{c}{ Covas Vazias (68,89\%) } \\
\hline \multirow{2}{*}{ Com mudas } & \multirow{2}{*}{$54,76 \%$} & Mudas mortas & $41,94 \%$ \\
& & Mudas arrancadas & $5,91 \%$ \\
\multirow{2}{*}{ Com pinhões } & \multirow{2}{*}{$45,24 \%$} & Pinhões mortos & $2,15 \%$ \\
& & Pinhões arrancados & $43,55 \%$ \\
\hline
\end{tabular}

TABELA 2: Teste de Tukey modificado para as variáveis "mortalidade" e "remoção" de mudas e sementes. TABLE 2: Modified Tukey's test for the variables "mortality" and "pullout" of seedlings and seeds

\begin{tabular}{lcc}
\hline \multicolumn{1}{c}{ Tratamento } & Mortalidade (\%) & Remoção pela fauna (\%) \\
\hline I Plantio puro de mudas & $52,22^{\mathrm{a}}$ & $6,67^{\mathrm{a}}$ \\
II Semeadura pura de pinhões & $3,33^{\mathrm{b}}$ & $68,89^{\mathrm{b}}$ \\
III Plantio de mudas em parcela mista & $68,89^{\mathrm{a}}$ & $11,11^{\mathrm{a}}$ \\
IV Semeadura de pinhões em parcela mista & $2,22^{\mathrm{b}}$ & $42,22^{\mathrm{a}}$ \\
\hline
\end{tabular}

Em que: Letras diferentes indicam diferença significativa entre os tratamentos em nível de $5 \%$ de probabilidade.

(p-valor $=0,017892)$. De forma geral, a plântula proveniente de semente é o material mais arrancado, principalmente no caso da semeadura em plantios puros; no caso das mudas, os índices de plantas removidas independem do tipo de arranjo utilizado (puro ou misto) (Tabela 2).

\section{CONCLUSÃO}

O percentual de germinação dos pinhões foi de $55 \%$ quando estes se encontravam em plantio puro e de $59 \%$ quando em plantio misto, perfazendo um percentual médio de germinação de $57 \%$. No entanto, considerando a ação da fauna consumidora, restaram apenas $14 \%$ das sementes germinadas no plantio puro e $28 \%$ no plantio misto, até o décimo quarto mês. Assim, as análises estatísticas demonstraram que as perdas das sementes germinadas foram significativamente maiores no caso do plantio com semeadura de forma homogênea (puro).

No que se refere às mudas, o percentual de sobrevivência médio foi de $41 \%$ no plantio puro e de $20 \%$ no plantio misto. Entretanto, neste caso, o número de mudas removidas pela fauna e a mortalidade foram significativamente maiores no plantio misto.

De maneira geral, as análises estatísticas demonstraram que a mortalidade independe do tipo de arranjo utilizado, sendo influenciada somente pelo tipo de material. Desta forma, a mortalidade do material do tipo "muda" foi significativamente maior do que no caso das sementes. Em contrapartida, no que diz respeito ao índice de remoção ocasionada pela fauna, este depende tanto do arranjo quanto do tipo de material, sendo as sementes significativamente mais arrancadas do que as mudas, principalmente quando em plantio puro.

Apesar de os pinhões semeados gerarem plântulas mais resistentes e mais bem adaptadas em campo, apresentando menores taxas de mortalidade natural, os resultados do presente estudo sugerem que o plantio de mudas pode proporcionar maiores índices de sucesso no estabelecimento de povoamentos de Araucaria angustifolia. Nesse caso, o fator determinante é a intensidade de predação da fauna e sua aparente preferência pelas mudas recém-emergidas das sementes. Por outro lado, a sobrevivência de mudas plantadas depende diretamente de sua qualidade, vitalidade, cuidados recebidos no viveiro e das condições climáticas encontradas durante a fase de implantação.

\section{REFERÊNCIAS BIBLIOGRÁFICAS}

ANSELMINI, J. I. Fenologia reprodutiva da Araucaria angustifolia (Bert.) O. Ktze, na região de Curitiba-PR. 2005. 62 f. Dissertação (Mestrado 
em Agronomia) - Universidade Federal do Paraná, Curitiba, 2005.

BACKES, A. Distribuição geográfica atual da Floresta com Araucária: condicionamento climático. In: FONSECA, C. R. et al. (Eds.). Floresta com araucária: ecologia, conservação e desenvolvimento sustentável. Ribeirão Preto: Holos, 2009a. p. 39-44.

BACKES, A. Floresta com Araucária: importância e usos múltiplos. In: FONSECA, C. R. et al. (Eds.). Floresta com araucária: ecologia, conservação e desenvolvimento sustentável. Ribeirão Preto: Holos, 2009b. p. 303-309.

BANCO REGIONAL DE DESENVOLVIMENTO DO EXTREMO SUL. Agência de Florianópolis. Gerência de Planejamento. Cultivo da Araucaria angustifolia: análise de viabilidade econômicofinanceira. Florianópolis: BRDE, 2005. 53 p.

CARVALHO, P. E. R. Competição entre espécies florestais nativas em Irati-PR, cinco anos após o plantio. Pesquisa Florestal, Colombo, n. 2, p. 41-56, 1981.

CARVALHO, P. E. R. Espécies florestais brasileiras: recomendações silviculturais, potencialidades e uso da madeira. Colombo: Embrapa-CNPF/SPI, 1994. 639 p.

FONSECA, J. M. M. A.; AGUIAR, L. B.; FERNANDES, P. D. Comportamento florestal de essências nativas e exóticas em condições de arboreto. Científica, Jaboticabal, n. 2, v. 2, p. 198207, 1974.

GANADE, G.; ZANINI, L. Restauração de floresta com araucária em áreas degradadas. In: FONSECA, C. R. et al. (Eds.). Floresta com araucária: ecologia, conservação e desenvolvimento sustentável. Ribeirão Preto: Holos, 2009. p. 85-95.

GUERRA, M. P. et al. Exploração, manejo e conservação da araucária (Araucaria angustifolia). In: SIMÕES, L. L.; LINO, C. F. (Eds.). Sustentável Mata Atlântica: a exploração de seus recursos florestais. São Paulo: SENAC, 2000. p. 85-101.

JANKAUSKIS, J. Ensaio de plantio de Araucaria angustifolia (Bert.) O. Ktze. Floresta, Curitiba, v. 4, n.1, p. 54-63, 1972.

KUNIYOSHI, Y. S. Morfologia da semente e da germinação de 25 espécies arbóreas de uma floresta com araucária. 1983. 245 f. Dissertação (Mestrado em Ciências Florestais) - Universidade Federal do Paraná, Curitiba, 1983.

LAMBERTS, A. V. D. H. Predação e sobrevivência de sementes de Araucaria angustifolia (Bert).
Kuntze em áreas de mata nativa e plantações de Pinus eliotti na Floresta Nacional de São Francisco de Paula, RS. 2003. 86 f. Dissertação (Mestrado em Ecologia) - Universidade Estadual de Campinas, Campinas, 2003.

LUDWIG, G.; AGUIAR, L. M.; ROCHA, V. J. Uma avaliação da dieta, da área de vida e das estimativas populacionais de Sapajus nigritus (Goldfuss, 1809) em um fragmento florestal no norte do Estado do Paraná. Neotropical Primates, Flórida, v. 13, n. 3, p. 12-18, 2005.

MELLO FILHO, J.A.; STOEHR, G. W. D.; FABER, J. Determinação dos danos causados pela fauna a sementes e mudas de "Araucaria angustifolia" (Bert.) O. Ktze. nos processos de regeneração natural e artificial. Floresta, Curitiba, v. 12, p. 26-44, 1981.

MULLER, J. A. A influência dos roedores e aves na regeneração da Araucaria angustifolia (Bert.) O. Ktze. 1986. 77 f. Dissertação (Mestrado em Ciências) - Universidade Federal do Paraná, Curitiba, 1986.

MUNIZ, P. J. C. Notas sobre uma plantação experimental de pinheiro-do-paraná (Araucaria brasiliana A. Rid.) nos solos de Campos Gerais. Arquivos de Biologia e Tecnologia, Curitiba, v. 8, p. 31-43, 1948.

PALUDO, G. F.; MANTOVANI, A.; REIS, M. S. dos. Regeneração natural de uma população natural de Araucaria angustifolia (Araucariaceae). Árvore, Viçosa, v. 35, n. 5, p. 1107-1119, 2011.

ROSOT, M. A. D. et al. Bosque Modelo Caçador: concepção e processo de estruturação. Colombo: Embrapa Florestas, 2013. 102 p. (Documentos, 258).

ROSOT, N. C. et al. Ações de recuperação em áreas degradadas por fogo em Floresta Ombrófila Mista: resultados parciais. Pesquisa Florestal Brasileira, Colombo, n. 54, p. 9, 2007.

SANQUETTA, C. R. Controle de taquaras como alternativa para a recuperação da Floresta de Araucária. Pesquisa Florestal Brasileira, Colombo, n. 55, p. 45-53, 2007.

SANQUETTA, C. R. et al. Sobrevivência de mudas de Araucaria angustifolia perante o controle de taquaras (Bambusoideae) no Paraná, Brasil. Floresta, Curitiba, v. 35, n. 1, SANQUETTA, C. R. p. 127-135, 2005.

TORTATO, M. A. Estudo de mamíferos em parcelas permanentes: o exemplo da Reserva Florestal da Embrapa/Epagri, Caçador, Santa Catarina. In: SEMINÁRIO NACIONAL SOBRE DINÂMICA 
DE FLORESTAS, 1., 2008, Curitiba, PR. Anais... Buenos Aires: FAO, 2009.

Colombo: Embrapa Florestas. CD-ROM.

SANQUETTA, C. R. et al. Mamíferos silvestres y su relación com la dinámica de un Bosque de Araucaria en el sur de de Brasil. In: CONGRESSO FORESTAL MUNDIAL, 13., 2009, Resumos... VIEIRA, E. M., IOB, G. Dispersão e predação de sementes de Araucaria angustifolia. In: FONSECA, C. R. et al. (Eds.). Floresta com araucária: ecologia, conservação e desenvolvimento sustentável. Ribeirão Preto: Holos, 2009. p. 85-95.

Ci. Fl., v. 26, n. 4, out.-dez., 2016 